\title{
La imagen de la mujer pintora en la ilustración popular del siglo XIX
}

\author{
Ma DOLOREs BASTIDA DE LA CALLE
}

El discurso de to marginal, que el arte del siglo XIX reclamaba como algo propio, encontró en la mujer un tópico social de especial significación para un siglo marcado por rápidas transformaciones. En apropiada correspondencia con su carácter de movimiento artístico marginal, la ilustración, y en particular la caricatura, iconografías populares cuyos códigos de representación eran simples y obvios, trataron muy especialmente aquellos tipos sociales que, por encontrase en proceso de evolución, resaltaban sobre el friso estático de la sociedad. La atención que prestaron las publicaciones ilustradas hacia los fenómenos marginales ha supuesto una ayuda notable para la historia social; tales publicaciones, aunque moderadas, disfrutaban de una difusión masiva, por lo que constituyeron una relevante fuerza ideológica y desempeñaron un importante papel en la formulación de una visión crítica.

En la literatura inglesa y norteamericana, el tema de la mujer pintora, en particular en el siglo XIX, ha sido intensamente analizado durante los últimos veinte años ${ }^{1}$. Estos estudios, unos de carácter general, otros centrados en la reivindicación de una serie de artistas no suficientemente valoradas o conocidas, han tratado de demostrar hasta que punto sus obras han sido víctimas de una valoración negativa por tratarse de mujeres, o bien, en una consideración aún más importante, han sido afectadas negativamente por la presión de una sociedad patriarcal que oprimía a las artistas. En España ha habido un reciente e interesante estudio de Estrella de Diego, limitado al ámbito nacional ${ }^{2}$. Aparentemente, sin embargo, no

CHERRY, Deborah, Painting Women. Victorian women artists. Londres, Routledge, 1993; GARB, Tamar, "Gender and Representatión» en Modernity and Modernism. French Painting in the Nineteenth Century. New Haven y Londres, Yale University Press y The Open University, 1993; CHADWICK, Whitney, Women, Art, and Society. Nueva York, Thames and Hudson, 1990.

2 Diego, Estrella de, La Mujer y la Pintura en la España del siglo xix. Mujeres pintoras en Madrid: 1868-1910. Tesis doctoral. Universidad Complutense de Madrid, 1987. 
existe análisis alguno de la imagen de la mujer pintora plasmada en la ilustración popular del siglo XIX, en especial en las publicaciones periódicas. En este breve artículo, sólo se pretende resaltar las posibilidades de investigación que presenta el tema.

Una primera faceta de esa imagen refleja la consideración que prestó la sociedad a la mujer que rechazaba la condición de artista amateur. Su tenacidad en la búsqueda de una realización profesional fue un motivo fácil para el caricaturista (fig. 1). En particular, las escenas en las que la artista se enfrentaba a un desnudo masculino ofrecieron amplias oportunidades para el humor lascivo (fig. 2). De hecho, era común la opinión de que el estudio del modelo masculino suponía un peligro moral para la mujer estudiante, y una fácil ocasión para la transgresión de las convenciones de feminidad. Estrella de Diego ha señalado que no hay noticia de alumnas matriculadas en La Escuela Especial de Pintura, Escultura y Grabado, en Madrid, hasta el curso 1878-79, año en que ya se nota una curiosa ausencia que perdurará a lo largo del siglo: No hay mujeres matriculadas en la asignatura de Anatomía Pictórica ${ }^{3}$.

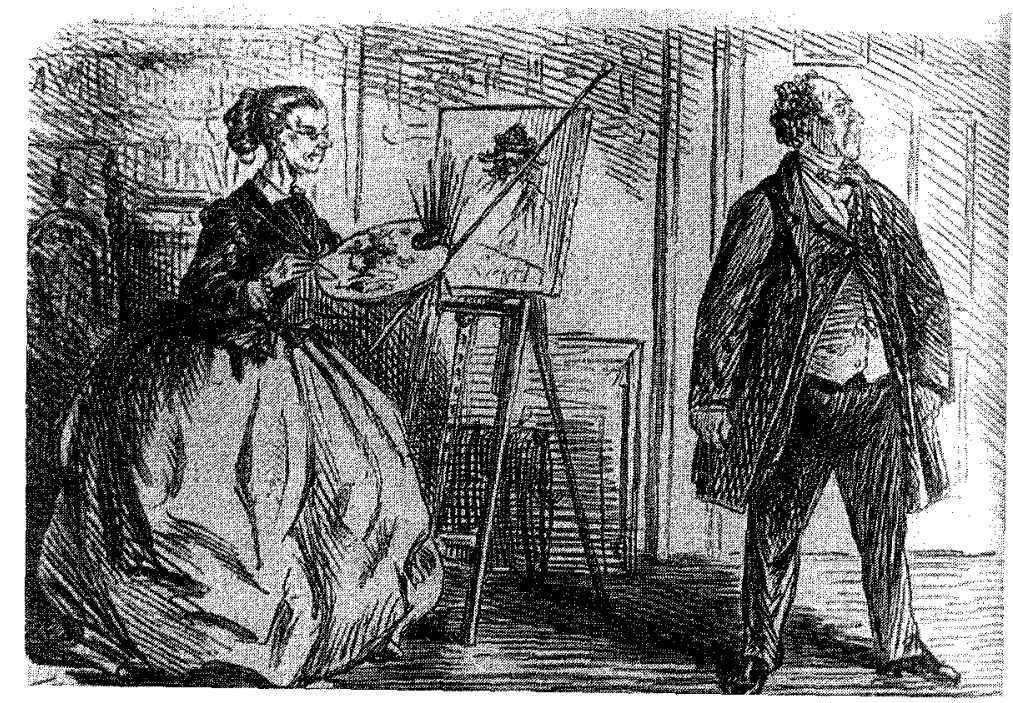

Fig. 1. Shocking incident in real life. Punch, 24 de septiembre de 1864

3 Ibidem, pág. 471. 


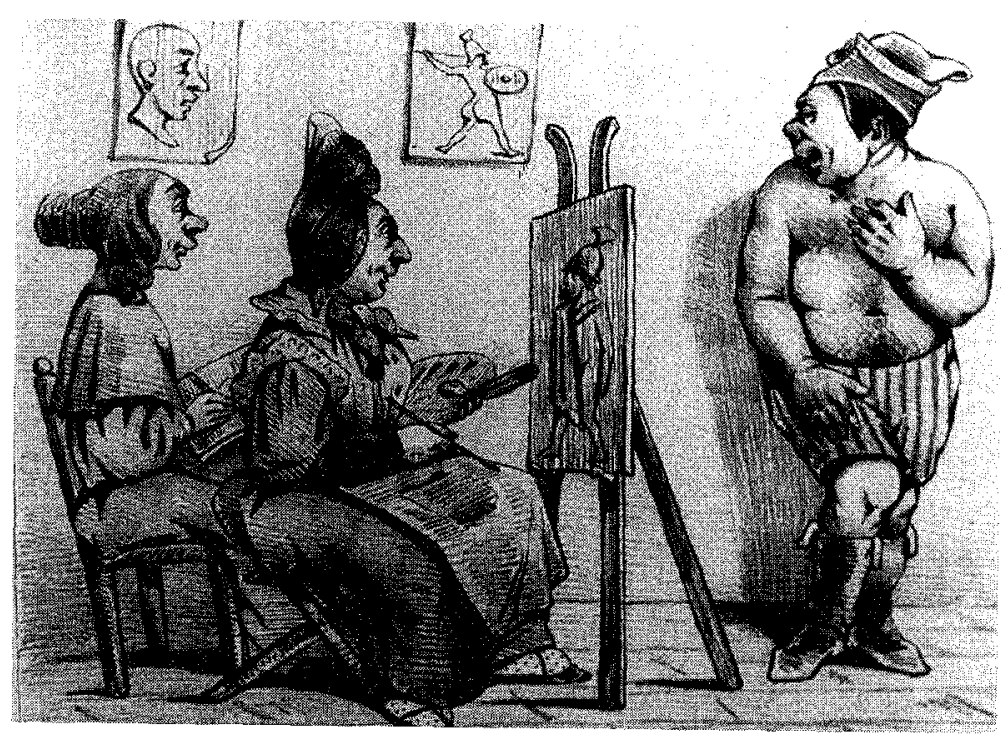

Fig. 2. «Allons Darancourt, gros indécent». Litografía de Pièces sur les arts. (Biblioteca Nacional de París)

En Gran Bretaña, punta de lanza del cambio social durante el siglo xIX, el temido peligro moral llevó a una prolongada exclusión de la mujer victoriana, de las Escuelas de la Royal Academy. La existencia de la Female School of Art and Design, una escuela oficial británica fundada en 1843, ofreció una excusa para la no admisión de mujeres a las enseñanzas de la Real Academia. Hubo, sin embargo, numerosas y repetidas solicitudes de admisión por estudiantes no satisfechas con el aprendizaje en la Female School, o en centros privados. En 1860, Laura Herford burló los controles de ingreso inscribiéndose bajo el nombre de $L$. Herford ${ }^{4}$; aunque en 1867 la Academia se abrió definitivamente a las estudiantes de Arte, estas adoptaron a menudo una aptitud polémica ante el temor a una expulsión. Florence Fenwick llamó la atención sobre el tema en su columna del Illustrated London News del 21 de diciembre de 1889. Esta revista, como otras publicaciones ilustradas con noticias de actualidad, participaron de la actitud condescendiente y paternalista de las autoridades académicas, ofreciendo otra faceta en la imagen de la mujer pintora, representada

4 Cherry, Deborah, Op. cit., pág. 57. 
ahora en una perenne fase de aprendizaje, incapaz de sobrepasar una cierta condición de amateur (figs. 3 y 4).

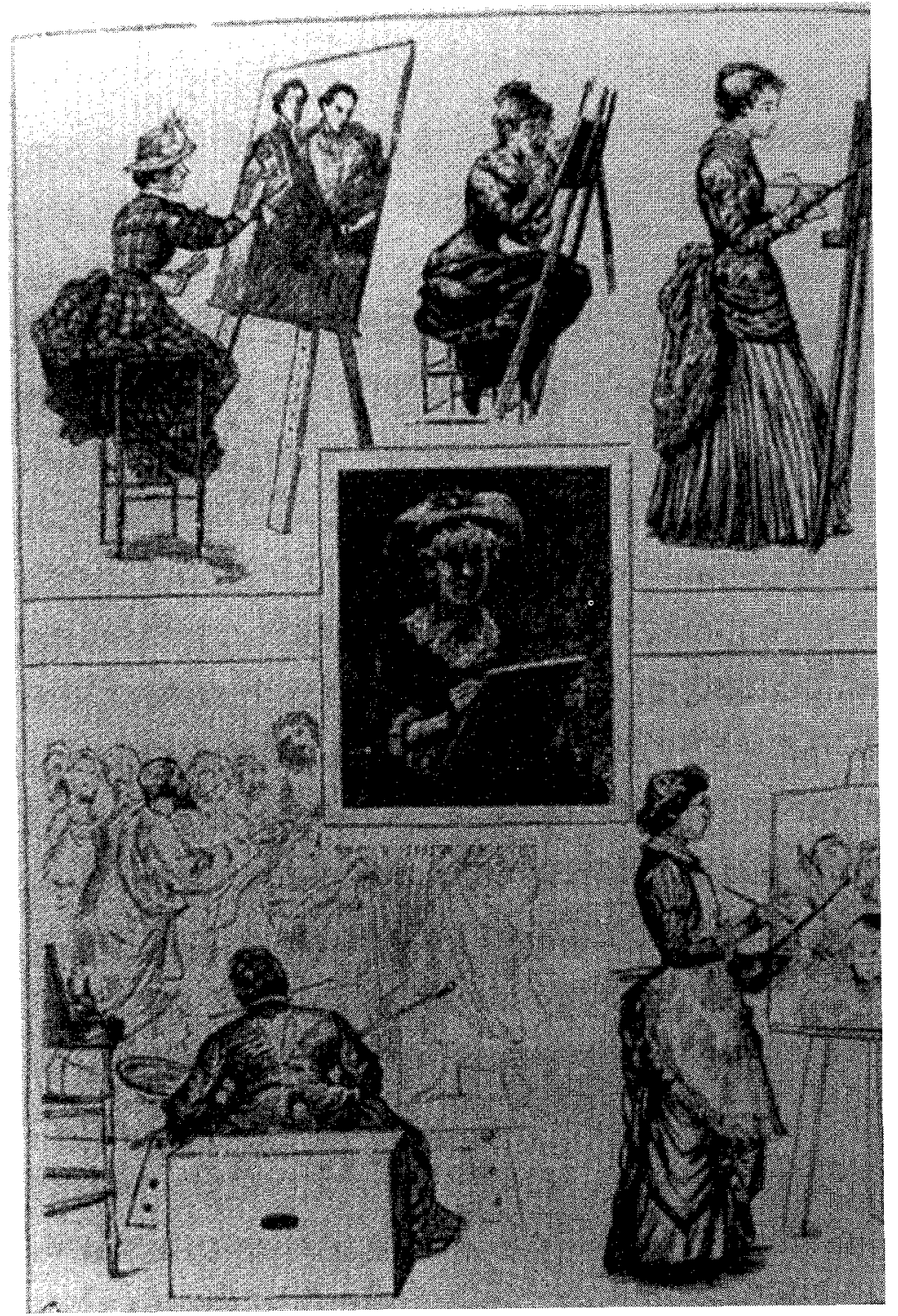

Fig. 3. Lady Students at the National Gallery. Alustrated London News, 21 de noviembre de 1885 


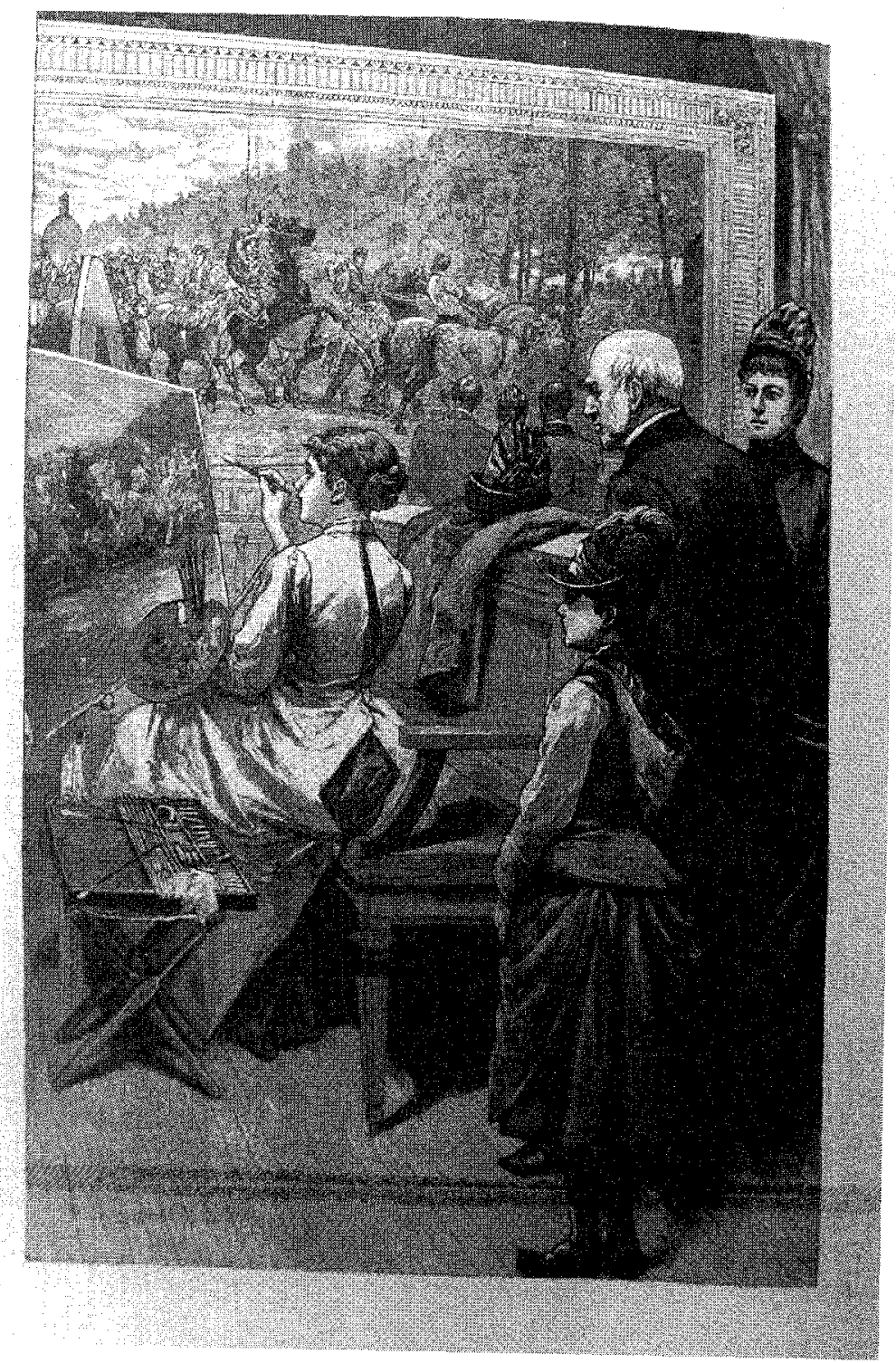

Fig. 4. Copying at the Metropolitan Museum. Frank Leslie's Illustrated Newspaper, 26 de mayo de 1888 
El posicionamiento paternalista de la sociedad victoriana para con la mujer llevaba asociado un generalizado convencimiento de su inferioridad, lo que encuentra una excelente ilustración literaria en un clásico de la novela de misterio, The Woman in White de Wilkie Collins ${ }^{5}$, sobre una mujer desposeída de su identidad. Collins estaba preocupado por el status ambivalente de la mujer victoriana (protegida y en consecuencia incapacitada para la vida independiente), tema al que volvió en 1862, en su novela No Name. El escritor, hijo y ahijado de pintores, amigo de Everett Millais, era aficionado al arte; de hecho, en The Woman in White el protagonista es un profesor de dibujo. A pesar de ello, Collins pone en boca de un inteligente personaje femenino de la novela juicios muy negativos sobre particulares aptitudes de la mujer, en especial en el campo de la creación artística. El personaje «no podia dejar de ver que... las mujeres, en general, practican las Bellas Artes de manera ridícula»; en su opinión «las mujeres no pueden dibujar, sus mentes son demasiado inconstantes y su mirada es incapaz de mantener la atención».

Las convenciones de la sociedad patriarcal coadyuvaron a definir una tercera temática visual, que codificaba a la artista misma como imagen. En ciertas publicaciones de la época la representación de instrumentos de pintura, como el caballete, la paleta y el pincel (fig. 5), que en sí mismos evocan un mundo de actividad profesional, se unen a convenciones standard en retratos de mujeres, representadas con profusión de adornos, lo que anula el significado de aquellos como signos de subversión del rol de la mujer burguesa ${ }^{6}$, a la que sólo la práctica amateur del arte estaba permitida. A este respecto, la imaginería de los medios gráficos también jugó un papel en la definición de los espacios de ámbito femenino. En una portada de la revista Gazette des femmes (fig. 6), que muestra varias viñetas, se produce una intersección de discursos sobre espacios público y doméstico. La estampa supone una interesante matización de la simplista formulación de un crítico de arte, John Berger, «men act and women appear». En las viñetas de ámbito domestico, se permite a la mujer aparecer actuando (como pintora o pianista amateur). Por el contrario, en la viñeta de la ópera, un espectáculo urbano abierto, ya a mediados del $x \mid x$, a la mujer de las grandes ciudades como Londres o París, ésta aparece, ahora en público, tan sólo como objeto de observación.

Collıns, Wilkie, The Woman in White. Ware (Gran Bretaña), Wordsworth, 1993.
GARB, Tamar, Op. cit., pág. 244. 


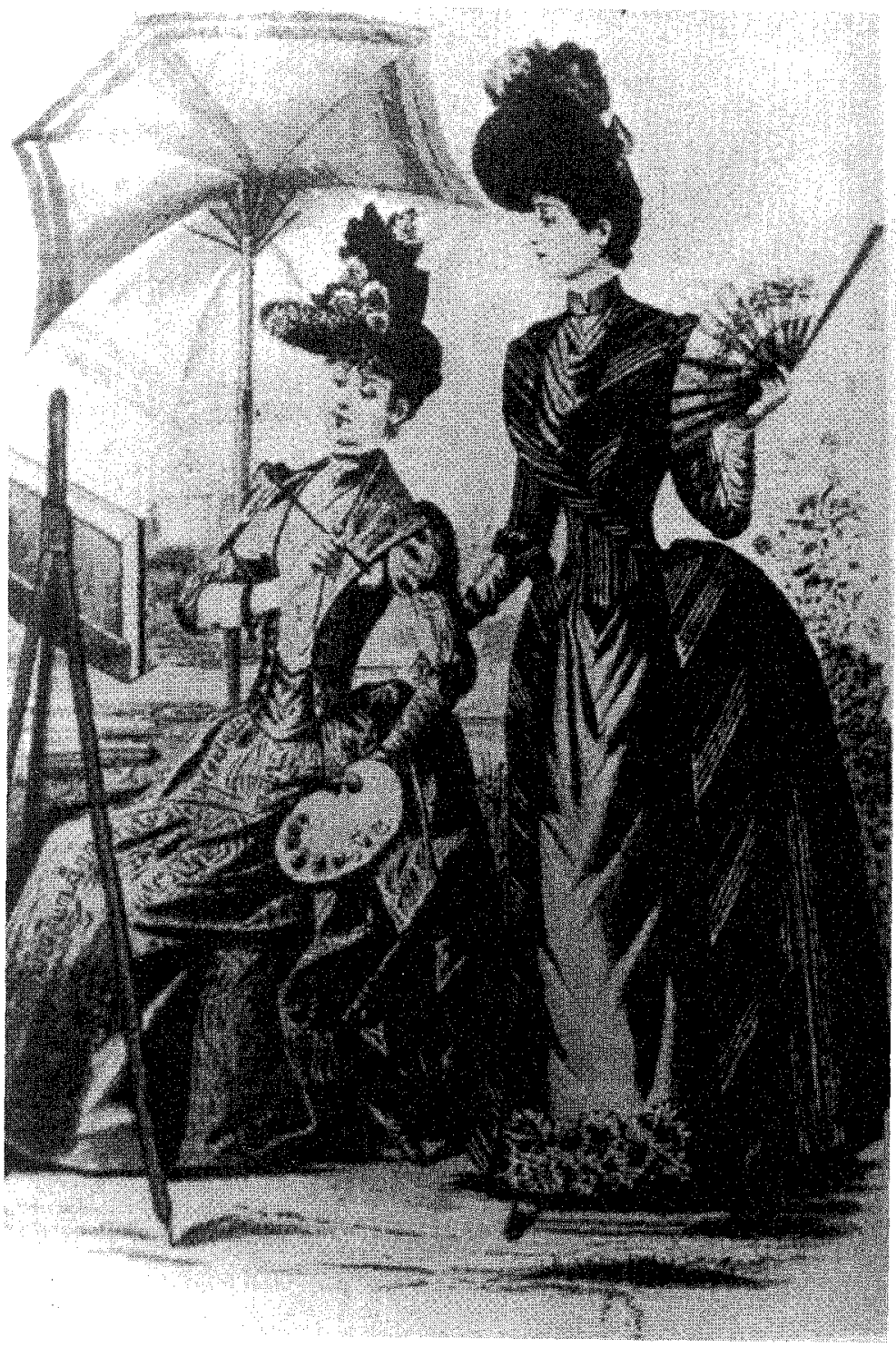

Fig. 5. Deux Femmes et un chevalet. Gazette des femmes. (Biblioteca Nacional de París) 


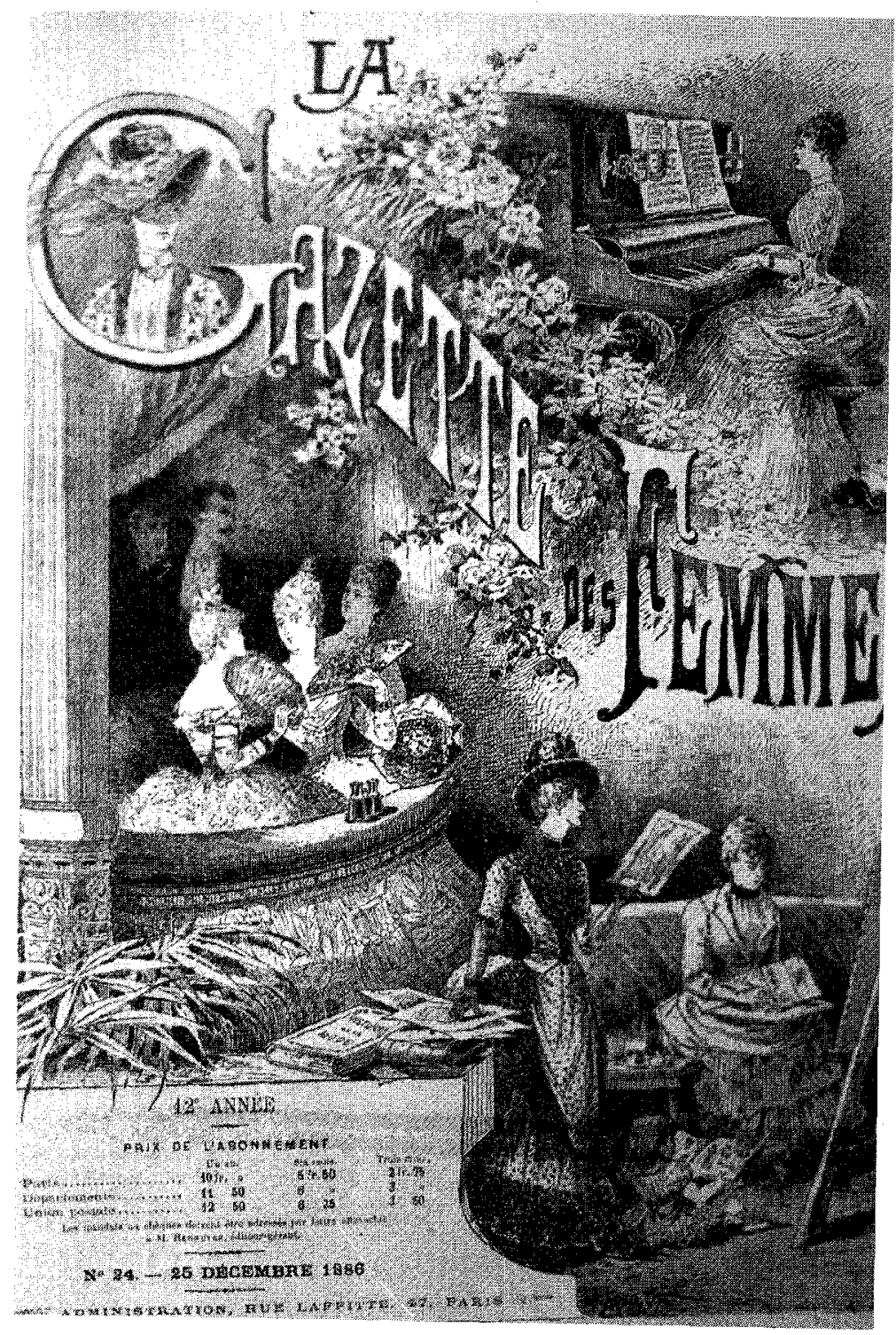

Fig. 6. Portada de Gazette des femmes, 25 de diciembre de 1886 
Por último, convendría resaltar que algunas pintoras del siglo xIX si adoptaron una temática considerada por la crítica como inadecuada para la condición femenina. Por ejemplo, Elizabeth Thompson, especialista en batallas, representó múltiples escenas de la guerra de Crimea; Rosa Bonheur trató insistentemente la imaginería animal. Ambas fueron muy apreciadas, sin embargo, por la sociedad de la época, y su peculiar temática aparece reflejada en ilustraciones de revista (en la fig. 4 una estudiante neoyorquina copia Horse Fair de Bonheur), a veces como motivo de caricatura (fig.7).

El siglo xIx fue, sin duda, el período histórico de mayor progreso social de la mujer, progreso tendente, en general, a la integración en actividades originalmente masculinas. En la actualidad, sin embargo, modernos movimientos feministas, como las Guerrilla Girls de Nueva York, centran su lucha, preferentemente, en un activismo artístico que enfatiza, entre otras cosas, los aspectos positivos de la separación de sexos. Esa actitud se traduce en eslóganes radicales que exaltan la comunidad de proyectos entre pintoras y las ventajas de ser mujer artista («Not having to be in shows with men»; «Being reassured that whatever kind of art you make, it will be labelled feminine» 7 ), en un peculiar y voluntario retorno a la tradición sexista del pasado.

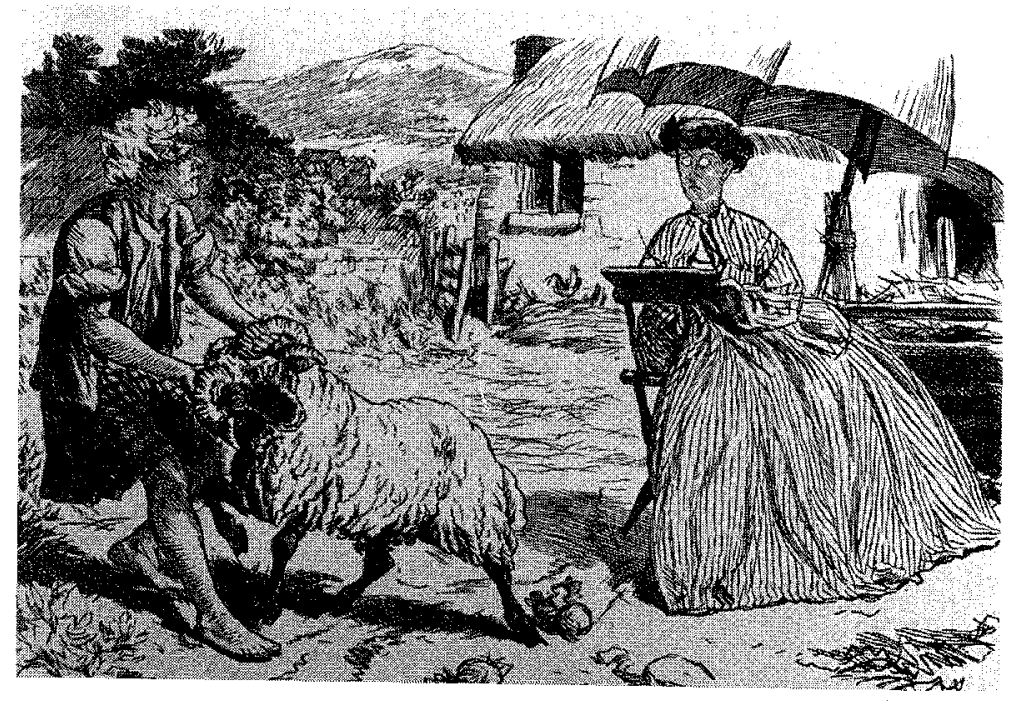

Fig. 7. The Adventures of Miss Lavinia Broujones. Punch, 1866

\footnotetext{
7 CHadwick, Whitney, Op. cit., pág. 351.
} 
$\therefore$ 